\title{
Assessment of Post Traumatic Stress and Its Pre-Traumatic Factors among Liberian Refugees in Nigeria.
}

\author{
Mokuolu Bolade Olubunmi Ph.D, Yarseah Alphonso Dogbahgeen \\ Department of Psychology Faculty of the Social Sciences Ekiti State University, P.O.Box 2002, Ado Ekiti \\ Nigeria.
}

\begin{abstract}
The study is a survey research carried out among Liberian refugees in Oru refugee camp to assess the prevalence of PTSD among the Liberia refugees in Nigeria and the impact of some pre-trauma factors on the experience of PTSD. Purposive random sampling was employed to select participants which consisted of 94 males and 73 females. Post traumatic disorder Checklist (PCL Civilian version) developed by Frank Weathers was used to measure their level of PTSD. The result shows that 74\% of the refugees scored above the norm $\chi=60.18$. there is a significant main effect of marital status and also significant interaction effect of gender and age.
\end{abstract}

Key Words: Post-traumatic stress, Pre-traumatic factors, Refugee,

\section{Introduction}

Liberia the second oldest African country after Ethiopia got her independence in 1847 but was being ruled from 1847 to 1980 by American-Liberian who regarded themselves as superior to the indigenous Liberian, a concept that led to repression and marginalization of the native Liberian which gave birth to her first coup d'état in 1980 headed by sergeant Samuel Kenyor Doe (kemp 2005). He too upon taking over the government became dictatorial and tribalistic. This led to strong indignation against his government. This made Charles Taylor, the deputy minister of economic affairs under the government of Samuel Doe, to find his way to Libya where he recruited likeminded Liberians and underwent military training with them in order to overthrow the Doe's government. This led Liberian civil war in 1989 that lasted for almost two decades. The first phase of the war ended in 1996. The sole aim was to upset government of president Doe but it degenerated into tribal war. The psychological distress of these people overflowed as their grief, shame, anxiety, depression, guilt and sorrow could not be allowed to be expressed publicly as any expression of sadness could be interpreted to mean that one is an enemy of government or rebels as the case may be, grief, depression and anxiety were forced to be suppressed in both govt and rebels controlled areas as nobody could be found to shed tears when any of these people were killed for the only crime of belonging to a particular ethnic group. Many people escaped for their lives to neighbouring countries, some of whom were brought to Nigeria at Oru refugee camp.

They escaped from the war only to cope with the psychological and emotional distress associated with physical and psychological abuses meted out to them by both rebels and government forces. These escapees referred to as refugees are the population of interest for this research work, in order to assess if they still suffer from PTSD.

Owing to the fact that a nation or community may face traumatic events, not all individuals living therein might experience PTSD. This means that there are pre-traumatic factors like age, gender, marital status, education and other factors that might contribute to the development of post traumatic stress disorder. Indeed the war in Liberia is over, but the emotional and psychological effects are seemingly long lasting among the refugees. This explains why most Liberian refugees refused to return home irrespective of the suffering they experience outside their country. It testifies that disaster whether man-made or natural may be relatively short lived, but the emotional traumas associated with it do not end when the disaster is over or when the victim is rescued. In some cases the aftermath of post traumatic stress may delay for days, months or years afterward; because after a stimulus associated with the traumatic event triggers memories of the victim, it may lead to depression, anxiety and other psychological and physiological responses, which might set in and endanger the refugees' basic assumptions and beliefs and thereby destroying them (Benson, 2006; Ehrereich,2001).

Trauma according to Omoluabi (2004) is defined as a psychological or physical injury that is caused by critical life events. These critical life events, in the case of the refugees can be referred to include rape, murder, torture, kidnapping, imprisonment, separation from family members, being forced to kill a friend or relative, witnessing the killing of a loved one or family among others. These events might overwhelm one with anxiety, depression, shame and difficulty in concentrating, insomnia, suspicion, irritability and hostility. For some others, sleep is disturbed by nightmares, flashbacks and for others; it may result in avoidance of people, places and situations that might trigger reminder of the event. 
Post traumatic stress disorder according to Halgin and Whitbourne (2007) has been described as an anxiety disorder in which the individual experiences several distressing symptoms for more than a month following traumatic event such as a re-experiencing of the traumatic event, avoidance and reminder of the trauma, a numbing in general responsiveness and increase arousal. Olowu (2002) also defined the concept as a psychological condition that derives from traumatic experience, which is beyond the victims' coping ability. It can then be deduced that the reason PTSD would exceed the coping ability of a refugee could be the process of experiencing and re-experiencing the stressor which do sometimes come by means of nightmares, flash back, or hallucination.

It has been observed that PTSD is the most common mental illness among refugees (Benson 2004; Colorado 2008 and UNHCR 2011). It has the potential of destroying their basic assumptions of the self, the future and world, making them to feel that life would not be the same again. The hallmark in getting scientific insight and understanding of these refugees' mental and psychological problems is to assess the prevalence of PTSD.

While PTSD is a by product of traumatic events, there are some risk factors for its development. Demographic variables such as age, gender, education, marital status, place identified as home, international travel all have some potentials in contributing to the existence and development of the disorder.

1.2 Purpose: The purpose of this study is to assess the prevalence of PTSD among Liberian refugees in Nigeria and also to examine the impact of social demographic variables which can otherwise be referred to as pretraumatic factors on the experience of PTSD among the Liberian refugees in Oru, Nigeria.

\section{Methods}

2.1 Participants: This is a survey research, carried out among the Liberian refugees that are living in Oru refugees camp in Ogun State, Nigeria. Although there are other refugees from other counties such as Sierra Leone, Chad and Democratic Republic of Congo. Purposive random sampling technique was employed to select the participants as refugees from Liberia were purposively chosen. Two hundred refugees participated in the research work, although only 167 copies of questionnaire were valid for use. This include 94 male and 73 females, out of which 85 were single, 65married, 8 widowed and 7 divorced.

2.2 Instrument Post Traumatic Stress Disorder Checklist (PCL Civilian version) developed by Frank Weathers 1993 was employed to measure the level of PTSD. The scale contains 17 items in which respondents are expected to respond to how they have been bothered by each symptom for the past month, on a 5point severity score. The scoring is done by adding up all the items for a total severity score. A total of 44 is considered to be PTSD positive. The items in the PCL were made to address three areas of DSM -IV symptoms of PTSD which include re-experiencing symptoms (items 1-5), emotional avoidance symptoms (items 6-12); and hyper arousal symptoms (13-17). Venteya, Yao, Cottanix, Note and Gilliland (2002) reported validity of .86 and a test re-test reliability of .80 for individuals in France who had experienced a severity of events. Because this instrument has not enjoyed popular usage in Nigeria, a two weeks test-retest reliability was carried out among 40 Sierra Leonean refugee that lived in Nigeria with the coefficient of 0.89 .

2.3 Procedure: the questionnaire is self administered, so it was distributed to the refugees, One of the researchers being a Liberian was familiar with the refugee camp and as well as the population of interest. With the permission of the camp authority, he was able to interact freely among the refugees. Few people who had problem reading it were assisted by reading it to them. Incentives in form of soap and pencils were also given to each participant for participating in the completion of the questionnaire.

III. Results

Table3.1: Independent t-test table showing the extent of PTSD among Liberia Refugees

\begin{tabular}{|c|c|c|c|c|c|c|c|}
\hline Variables & $\mathbf{N}$ & mean & SD & SE & Df & $\mathbf{t}$ & $\mathbf{p}$ \\
\hline $\begin{array}{l}\text { Experience } \\
\text { PTSD }\end{array}$ & 123 & 60.18 & 10.42 & 0.94 & \multirow[t]{2}{*}{165} & \multirow[t]{2}{*}{14.89} & \multirow[t]{2}{*}{$<.05$} \\
\hline $\begin{array}{l}\text { Do not } \\
\text { experience } \\
\text { PTSD }\end{array}$ & 44 & 34.38 & 8.08 & 1.22 & & & \\
\hline
\end{tabular}

Table 1 shows a significant difference in the scores of those who scored above average and those who scored below. $\mathrm{t}(165)=14.89, \quad \mathrm{p}<.05$. Only $44(26 \%)$ out of 167 which were assessed scored below the cut off point having a mean score of 34.38. this indicates that a large number of the refugees 127 (74\%) are actually experiencing PTSD with the mean score of 60.18 .

\section{Table 3.2: Descriptive table}


Assessment Of Post Traumatic Stress And Its Pre-Traumatic Factors Among Liberian Refugees In

\begin{tabular}{|c|c|c|c|c|}
\hline \multicolumn{2}{|l|}{ Variables } & $\mathbf{N}$ & Mean & SD \\
\hline & $16-25$ & 43 & 48.12 & 15.55 \\
\hline & $26-45$ & 101 & 54.94 & 14.04 \\
\hline & $46-65$ & 23 & 56.39 & 16.63 \\
\hline \multirow[t]{2}{*}{ Gender } & male & 94 & 51.86 & 15.56 \\
\hline & female & 73 & 55.34 & 14.24 \\
\hline \multirow[t]{4}{*}{ Education } & degree & 28 & 51.04 & 15.38 \\
\hline & Secondary & 93 & 53.19 & 14.66 \\
\hline & $<$ secondary & 43 & 55.60 & 15.51 \\
\hline & Post graduate & 3 & 49.33 & 21.22 \\
\hline \multirow[t]{4}{*}{ Marital status } & single & 87 & 51.89 & 1.58 \\
\hline & Married & 65 & 52.44 & 1.76 \\
\hline & Widow & 8 & 70.12 & 5.19 \\
\hline & Divorce & 7 & 61.43 & 6.19 \\
\hline \multirow[t]{2}{*}{ Religion } & Christianity & 149 & 52.93 & 15.95 \\
\hline & Islamic & 18 & 57.17 & 13.95 \\
\hline
\end{tabular}

Table 3.3: One way ANOVA table showing the effect of marital status on the experience of PTSD among the refugees

\begin{tabular}{|l|l|l|c|l|c|l|c|l|l|l|}
\hline & $\begin{array}{c}\text { Married } \\
\mathbf{n = 6 5}\end{array}$ & & $\begin{array}{c}\text { Single } \\
\mathbf{n = 8 7}\end{array}$ & & $\begin{array}{c}\text { Widow } \\
\mathbf{n = 8}\end{array}$ & & $\begin{array}{c}\text { Divorce } \\
\mathbf{n = 7}\end{array}$ & & & \\
\hline Variable & $X$ & SD & $\chi$ & SD & $X$ & SD & $\chi$ & SD & Group Effect & p \\
\hline PTSD & 52.44 & 1.76 & 51.89 & 1.58 & 70.12 & 5.19 & 61.43 & 6.19 & $\mathrm{~F}(3,166)=4.62$ & $<.05$ \\
\hline
\end{tabular}

Table3 shows that marital status has a significant effect on the experience of PTSD among Liberian refugees $\mathrm{F}(3,163)=4.62, \mathrm{p}<.05$. in order to ascertain the direction of the difference a scheffe post hoc analysis revealed that there is a significant difference between widows $(x=70.12)$ and single $(x=51.89)$; and also between widow and married $(x=52.44)$. however, the mean difference between single and married; married and divorced are not significant at .05 level.

Table 3.4: $2 \times 2 \times 3 \times 4$ ANOVA summary table showing the effects of the demographic variables on PTSD

\begin{tabular}{|l|l|l|l|l|l|}
\hline Source & SS & Df & MS & F & P \\
\hline Intercept & 108438.25 & 1 & 108438.25 & 520.58 & $<.05$ \\
\hline Gender & 459.99 & 1 & 459.99 & 2.21 & $>.05$ \\
\hline Religion & 484.46 & 1 & 484.46 & 2032 & $>.05$ \\
\hline Ages & 91.69 & 2 & 45.84 & 0.22 & $>.05$ \\
\hline Education & 516.36 & 3 & 172.12 & 0.83 & $>.05$ \\
\hline Gender*religion & 8.40 & 1 & 8.40 & 0.04 & $>.05$ \\
\hline Gender*age & 1880.75 & 2 & 940.37 & 4.51 & $<.05$ \\
\hline Gender*educ & 832.94 & 3 & 277.65 & 1.33 & $>.05$ \\
\hline Religion*age & 1015.38 & 2 & 507.69 & 2.43 & $>.05$ \\
\hline Religion*educ & 472.08 & 2 & 236.04 & 1013 & $>.05$ \\
\hline Age*educ & 1639.31 & 4 & 409.83 & 1.97 & $>.05$ \\
\hline Gender*relig*age & 221.96 & 1 & 221.96 & 1.07 & $>.05$ \\
\hline Gender*age*aduc & 291.07 & 4 & 72.77 & 0.35 & $>.05$ \\
\hline Relig*age*educ & 140.40 & 1 & 140.40 & 0.67 & $>.05$ \\
\hline Error & 28537.56 & 137 & 208.30 & & \\
\hline Total & 37603.47 & 166 & & & \\
\hline
\end{tabular}

Table 4 shows that the demographic variables do not have significant main effect on PTSD among the refugees. Although there is a significant interaction effect of gender and age. The post hoc analysis shows a significant difference between the mean score of individuals in age brackets 16-25 $(x=48.12)$ and $26-45(x=54.94)$; and those in 16-25 $(x=48.12)$ and 46-65 $(x=56.39)$ age brackets. Between those in age brackets $26-45$ and $46-65$ there is no significant difference. This shows that the younger age is not associated with PTSD in fact the mean score is below the average score of all the participants in PTSD. 


\subsection{Discussion}

\section{Conclusion}

Indeed the war in Liberia has been over since 1996, but the psychological effects are seemingly long lasting among refugees. These refugees have experienced objective trauma such as rape, destruction of life and properties, torture, beating a child or adult attacked with gun or other dangerous weapons. They have as well faced subjective traumas such as sudden loss of home and possessions, humiliation, breaking of relations, sudden separation from family members or friends as well as watching someone behaving cruelly and living in insanitary conditions. The finding of this study is consistent with previous studies in Rwanda, Sierra Leone, Sudan, and elsewhere around the world. In a study conducted by Ahmad et al (2000) in two displaced camps five years after the military operation in Iraq, Kurdistan, the result showed that PTSD was reported in $87 \%$ of the respondents who were refugees.

Research has discovered that people who are exposed to protracted disasters such as war, torture, rape, forced migration, and isolation as well as inordinate destruction of properties and lives may suffer from scatter assumptions and become self critical and people who are self critical and self attacked are $t$ high risk of psychopathology. Janoff -Bulman (1992); Gilbert, Balwin, mark, Chris, Jodene and Michelle (2006). Omoluabi (2001) and Bolton (2008) also reported that the challenge of refugees are not limited to where the trauma event occurred nor confined within the migration period but also extends to the refugees camp. In addition to the life threatening, stress experienced during the war, refugees frequently suffer recurrent losses, challenges and changes during exile. Having left homes, they are forced to confront isolation, hostility, violence and dehumanisation in their new location.

Widows have the highest level of PTSD followed by the divorced, then married and single. The widows might have lost their spouses in the war and this could bring about re-experiencing symptoms such as flashbacks, nightmares, psychological and physiological distress. It was discovered that in the trauma history of these refugees that $41.9 \%$ of the females and $37.2 \%$ of the males experienced broken relationship or divorce in the war, showing that almost half of the refugees who were married before or during the war got divorced. This might reduce the social support system and their well being, and increase their level of distress and vulnerability to stress and psychological well being.

Previous studies by Tull (2008) found that life time PTSD was more common among widows, divorced and married than individuals who were single. Kalayjian, Kamazi, Aberson and faygi (2002) also confirm the findings, that single person attain lower level of PTSD scores than married and divorced individuals. In another study comparing currently married and previously married, it was reported that those who were married but got divorced, separated or widowed had high rate of PTSD than those who were currently married and living together. However, a study carried out by Martz, Birks and Blackwell (2010) did not confirm the result of this study. They found that marital status failed to predict PTSD among veterans with disabilities. The reason for this disagreement could be that their study dealt with veterans who were exposed to physical combat and receiving treatments and compensation from the United State Government whereas this present study was conducted among refugees in a camp who had no special treatment.

From literature, findings show that there has been no consistent effect of age on PTSD. But only depend on the social, economic, cultural and historical context of the disaster stricken setting more than depended on age. Noris et.al (2002) found inconsistent results among respondents from the USA, Mexico and Poland, where the most distressed were the middle age, the young and old respectively. The result of this study shows a significant interaction effect of age and gender $[\mathrm{F}(2,137)=4.51, \mathrm{P}<.05]$ this is in consonance with a longitudinal a study by Denson (2007), and also among military and civilian population as reported by Brewin, Andrew and Valentine (2000). They reported PTSD, among women in their 50s and men in their 40s.

Also in this study, education do not have any significant effect on PTSD, although this do not agree with previous studies by Breslau, Davis, Andreski and peterson (1991), Karunakara, Nuener, Schauer, Singh, Hill, Elbert and Buruham (2004) and National Comorbidity Survey of the United States of America (2009) found that education predicted PTSD. The reason for the different result could be due to the timing of this current study, geographical location of the refugees' camp and some other individual factors. This present study took place almost after two decades of living in refugee camp where individuals' lives and values become meaningless. Also before the civil war, Liberia has one of the highest illiteracy rate in Africa. So it could be said that many of these refugees were not well education was no longer meaningful to them during the study.

Based on the findings of this study, it can be concluded that rate of PTSD was high among the Liberian refugees in Nigeria with at least $76 \%$ of them scoring above the norm. Some pre-traumatic factors such as marital status and age play significant role in the development of PTSD among the refugees; while factors such as education do not have either significant main or interaction effect on the development of PTSD. About 76\% of the refugees suffered from PTSD this implies that the possibility of developing PTSD and its comorbidity is high among people exposed to man-made disasters in view of this, Psychologists should investigate the traumatic experience further so as to obtain comprehensive record of possible etiological factors. There is also 
tendency that people with trauma history may develop not only PTSD but also psychological distress such as major depression and other types of anxiety disorders or stress either alone or in combination with PTSD

\subsection{Recommendation}

There is a need to pay attention to the mental health of individuals in the refugee camp, therefore mental health workers who are trained to handle PTSD should be stationed at the refugees camp in order to handle their traumatic conditions. More studies should be carried out in the area of comorbidity of PTSD with other psychological disorders and the coping pattern that could be employed to combat it

\section{References}

[1]. J. Benson, Third culture personalities and the integration of refugees into the community: some reflection from general practice. (2006)

[2]. E Bolton. Shame and guilt, misconception and controversies. A critical review of the literature. htt://www.sagepublication.com. (2008)

[3]. N. Breslau, G.C. Davis, M.A. Andreski, and E. Peterson, Traumatic events and urban population of young adults. Archives of General Psychiatry, 48; (1991) 216-222

[4]. C.R Brewin, B. Andrews, and J.D. Valentine, Meta analysis of risk factors for PTSD in Trauma exposed adults. Journal of Counselling and Clinical Psychology, 68 (5), (2000)748-766.

[5]. C. Colorado. How to support refugee students in the ELL classroom. http://www.accessmylibrary.com/summary. (2008)

[6]. J. H. Ehrenreich, Coping with disasters: Guide book to psychological intervention. http://www.mnwwa.on (2001)

[7]. P. Gilbert, M.W. Balwin, I.B. Chris, R. Jodene and P. Michelle, Self-criticism and self-warmth: an imaginary study exploring their relation to depression. Jounal of Clinical Psychotherapy. 20 (2006).

[8]. R. Haigin, and S.K. Whitbourne, Abnormal psychology : A clinical perspective on psychological disorders. New York. McGraw Hill. (2007)

[9]. R. Janoff-Bulman, Scattered assumptions: Toward a new psychology of trauma. New York: Maxwell Macmillan International. (1992)

[10]. Kalayjaian, R.L. Kanazi, C.L. Aberson, L. Faygi, A cross-cultural study of the psychosocial and spiritual impact of natural disaster. International Journal of Group tensions. 31 (2002) 175-186

[11]. U.K. Karunakara, F. Nuener, M. Schauer, K. Snigh, K. Hill, T. Elbert, G. Buruham, Traumatic events and symptoms of posttraumatic stress disorder amongst Sudanese nationals, refugees and Ugandans in West Nile African. Heallth Science. 4(2) (2004) 83-93.

[12]. C. Kemp, A brief history of the conflict in Liberia. http://www.History/Liberia/conflict/htm (2005)

[13]. E. Martz, K. Birks, and Blackwell the prediction of levels of posttraumatic stress levels by depression among veterans disabilities. Journal of Rehabilitation. (2011)

[14]. F.H. Norris, J.L. Perilla, G.E. Ibanez, and A.D. Murphy, Sex differences in symptoms of posttraumatic stress: does culture play a role? Journal of traumatic stress. (2002) 